\title{
High-resolution inventory of ammonia emissions from agricultural fertilizer in China from 1978 to 2008
}

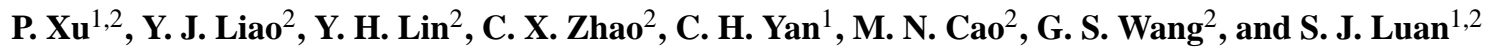 \\ ${ }^{1}$ College of Environmental Sciences and Engineering, Peking University, Beijing 100871, China \\ ${ }^{2}$ Key Laboratory for Urban Habitat Environmental Science and Technology, School of Environment and Energy, \\ Peking University Shenzhen Graduate School, Shenzhen 518055, China \\ Correspondence to: S. J. Luan (luansj@pkusz.edu.cn)
}

Received: 20 August 2015 - Published in Atmos. Chem. Phys. Discuss.: 16 September 2015

Revised: 21 December 2015 - Accepted: 14 January 2016 - Published: 3 February 2016

\begin{abstract}
The quantification of ammonia $\left(\mathrm{NH}_{3}\right)$ emissions is essential to the more accurate quantification of atmospheric nitrogen deposition, improved air quality and the assessment of ammonia-related agricultural policy and climate mitigation strategies. The quantity, geographic distribution and historical trends of these emissions remain largely uncertain. In this paper, a new Chinese agricultural fertilizer $\mathrm{NH}_{3}$ $\left(\mathrm{CAF} \_\mathrm{NH}_{3}\right)$ emissions inventory has been compiled that exhibits the following improvements: (1) a $1 \times 1 \mathrm{~km}$ gridded map on the county level was developed for 2008; (2) a combined bottom-up and top-down method was used for the local correction of emission factors (EFs) and parameters; (3) the temporal patterns of historical time trends for 19782008 were estimated and the uncertainties were quantified for the inventories; and (4) a sensitivity test was performed in which a province-level disaggregated map was compared with $\mathrm{CAF} \_\mathrm{NH}_{3}$ emissions for 2008. The total CAF_NH emissions for 2008 were $8.4 \mathrm{TgNH}_{3} \mathrm{yr}^{-1}$ (a $6.6-9.8 \mathrm{Tg}$ interquartile range). From 1978 to 2008, annual $\mathrm{NH}_{3}$ emissions fluctuated with three peaks (1987, 1996 and 2005), and total emissions increased from 3.2 to $8.4 \mathrm{Tg}$ at an annual rate of $3.0 \%$. During the study period, the contribution of livestock manure spreading increased from 37.0 to $45.5 \%$ because of changing fertilization practices and the rapid increase in egg, milk, and meat consumption. The average contribution of synthetic fertilizer, which has a positive effect on crop yields, was approximately $38.3 \%$ (minimum: $33.4 \%$; maximum: $42.7 \%$ ). With rapid urbanization causing a decline in the rural population, the contribution of the rural excrement sector varied widely between $20.3 \%$ and $8.5 \%$. The average contributions of cake fertilizer and straw returning
\end{abstract}

were approximately 3.8 and $4.5 \%$, respectively, thus small and stable. Collectively, the $\mathrm{CAF}_{-} \mathrm{NH}_{3}$ emissions reflect the nation's agricultural policy to a certain extent. An effective approach to decreasing $\mathrm{PM}_{2.5}$ concentrations in China would be to simultaneously decrease $\mathrm{NO}_{x}, \mathrm{SO}_{2}$, and $\mathrm{NH}_{3}$ emissions.

\section{Introduction}

$\mathrm{NH}_{3}$ is a colorless alkaline gas with high reactive ability and solubility in the atmosphere, where its presence has undesirable consequences. The gas reacts with $\mathrm{HNO}_{3}$ and $\mathrm{H}_{2} \mathrm{SO}_{4}$ in the air to form ammonium salts $\left(\mathrm{NH}_{4} \mathrm{NO}_{3},\left(\mathrm{NH}_{4}\right)_{2} \mathrm{SO}_{4}\right.$ and $\left(\mathrm{NH}_{4}\right) \mathrm{HSO}_{4}$ ) (Pinder et al., 2007), which further contribute to visibility degradation and regional haze and have adverse health effects (Kim et al., 2006; Ye et al., 2011; Langridge et al., 2012). Such salts could account for $7.1-57 \%$ of the total quantity of atmospheric fine particulate matter $\left(\mathrm{PM}_{2.5}\right.$ : aerodynamic diameter of particle size $\leq 2.5 \mu \mathrm{m}$ ) (Yang et al., 2011; Huang et al., 2014; F. Zhang et al., 2014). $\mathrm{NH}_{3}$ comprises nearly half of all reactive nitrogen released into the atmosphere and plays a key role in soil acidification, eutrophication, and the disruption of ecosystems by dry deposition (Vanbreemen et al., 1984; Hellsten et al., 2008; Bouwman et al., 1997). In addition, although $\mathrm{NH}_{3}$ exerts a cooling effect on the planet as a result of radiation forcing by aerosol particles (Martin et al., 2004), it is an indirect source of the major greenhouse gas nitrous oxide from the Intergovernmental Panel on Climate Change (IPCC, 2006). Therefore, efforts to decrease $\mathrm{NH}_{3}$ emissions could have triple the benefit of slow- 
ing global climate change, decreasing regional air pollution and protecting human health (Zheng et al., 2012; Erisman et al., 2013).

Agriculture in China utilizes approximately $7 \%$ of the world's cultivated land area to support $22 \%$ of the global human population. To meet the demand for food of China's large and increasing population (30-50\% more food will be required over the next two decades) (Zhang et al., 2013; Cui et al., 2014; Ma et al., 2013), the government has initiated a series of agricultural policies that aim to increase the will of farmers, including farmers who overuse agricultural fertilizers (including synthetic and organic fertilizers), to increase yields. Policy-driven measures to increase the use of fertilizer and low nitrogen-use efficiency have resulted in continually increasing $\mathrm{NH}_{3}$ emissions (Vitousek et al., 2009; Gu et al., 2012; W. Zhang et al., 2014). Therefore, to achieve the balance of food demand and environment effects, $\mathrm{NH}_{3}$ emissions must be accurately estimated in a manner that reflects the spatial and temporal pattern of their sources.

Previous studies mainly estimated $\mathrm{NH}_{3}$ emissions in China based on EFs and activity. In the 1990s, China's $\mathrm{NH}_{3}$ emissions were estimated based on uniform or overseas EFs for the entire country (Sun and Wang, 1997; Wang et al., 1997; Olivier et al., 1998; Xing and Zhu, 2000; Streets et al., 2003; Yan et al., 2003), which decreased the accuracy of these estimates because of the differences in regional environmental conditions. Subsequent studies, in which national or provincial statistical data on the rural population, fertilizers and agricultural production were used to estimate $\mathrm{NH}_{3}$ emissions, generally downscaled to realize higher spatial resolution (e.g., Yamaji et al., 2004; Huang et al., 2012; EDGAR v.4.2, 2013). Thus, biases could occur. Paulot et al. (2014) improved the bottom-up emission inventory to incorporate sector-resolved information on global agricultural activities known as MASAGE_NH $\mathrm{NH}_{3}$, which is still limited to specific sectors, such as precipitation and the monitoring networks provide high-density data (Paulot et al., 2014). Additionally, the previous emission inventories provide no or only coarse temporal distributions during the year, which could result in underestimation during summer and overestimation during winter (Wang et al., 1997; Yan et al., 2003).

In addition, studies have attempted to focus on implementing the bidirectional exchange of $\mathrm{NH}_{3}$ in many air quality models, e.g., the Community Multi-scale Air Quality (CMAQ) model (Cooter et al., 2010; Bash et al., 2013; Pleim et al., 2013; Fu et al., 2015), and the GEOS-Chem global chemical transport model (Zhu et al., 2015). $\mathrm{NH}_{3}$ deposition, emission, re-emission, and atmospheric lifetime can be affected by rigorous treatment of the bidirectional flux of $\mathrm{NH}_{3}$, and vegetation and soil can be either a sink or a source of atmospheric $\mathrm{NH}_{3}$ (Sutton et al., 2007). Fu et al. (2015) provide the first online estimate of $\mathrm{NH}_{3}$ emissions from agricultural fertilizer use China, based on coupling the CMAQ model with a bi-directional $\mathrm{NH}_{3}$ exchange module and the Environmental Policy Integrated Climate (EPIC) model, this method considers an increased number of influencing factors, such as meteorological fields, soil and fertilizer application, and provides improved $\mathrm{NH}_{3}$ emissions with higher spatial and temporal resolution, whereas gaps still exist for this method owing to the uncertainties of more model parameterization and input data. Zhu et al. (2015) developed the adjoint of bidirectional exchange in GEOS-Chem model which suggests that although the implementing bidirectional exchange greatly extends the lifetime of $\mathrm{NH}_{3}$ in the atmosphere via deposition and re-emission processes and conducts a better fundamental description of $\mathrm{NH}_{3}$ emissions from fertilizers, it does not however uniformly ameliorate estimation of $\mathrm{NH}_{3}$ concentrations, $\mathrm{NH}_{4}^{+}$wet deposition, and nitrate aerosol concentrations due to the $\mathrm{NH}_{3}$ re-emissions from the ammonium soil pool that accumulates ammonium from previous months or the ammonium soil pool which preserves ammonia/ammonium in the soil rather than emitting it directly after fertilizer application during the growing seasons (e.g., bidirectional exchange significantly decreases $\mathrm{NH}_{3}$ gross emissions in southeastern China and $\mathrm{NH}_{3}$ concentrations in China in April of 2008, but changes in $\mathrm{NH}_{4}^{+}$wet deposition are not very large in April).

In this study, a $1 \times 1 \mathrm{~km}$ gridded new $\mathrm{CAF} \mathrm{NH}_{3}$ emission inventory based on county-level activity data was developed for 2008 and historical time series of $\mathrm{NH}_{3}$ emissions based on province-level activity data from 1978 to 2007. An effort was made to improve accuracy and decrease uncertainty by considering more comprehensive emission sources. In addition, a combined bottom-up and top-down method was used for the local correction of EFs and parameters. We analyzed the emission totals, source apportionment, spatial and temporal patterns and uncertainty, and compared our results with previous studies. Then, we compared the 2008 emission map with a province-level disaggregated map. We also provided a clear description of the change in $\mathrm{NH}_{3}$ emissions in CAF historical emissions between 1978 and 2008. Finally, the implications of the higher spatial and temporal resolution $\mathrm{NH}_{3}$ emission inventory are discussed, with a focus on the control of $\mathrm{N}$ deposition, the improvement of air quality, $\mathrm{NH}_{3}$ emission-related agricultural policy, and climate mitigation strategies.

\section{Methodology and data sources}

\section{1 $\mathrm{NH}_{3}$ emission sources}

Five $\mathrm{NH}_{3}$ emission sources, including synthetic fertilizers (i.e., chemical and compound fertilizers) and organic fertilizers (i.e., rural excrement, livestock manure spreading, cake fertilizer, and straw returning. In this study, straw returning represents crop residue compost which adds soil nutrients in rural China, and $\mathrm{NH}_{3}$ is released during composting through aerobic and anaerobic microbial processes. Sludge is not considered to be an agricultural fertilizer, and the quan- 
tity of green manure that is applied is limited) (Gao et al., 2011), are included in our emissions model. China's $\mathrm{NH}_{3}$ emissions from agricultural fertilizer $\left(E_{\mathrm{NH}_{3}}, \mathrm{TgNH}_{3} \mathrm{yr}^{-1}\right)$ are calculated with the following equation:

$E_{\mathrm{NH}_{3}}=\sum_{i} A_{n i j} \cdot \mathrm{EF}_{i j} \cdot f\left(\mathrm{RP}_{n i j m}, C_{m}\right)$,

where subscripts $n, i, j$, and $m$ are the year, the emission source, the region (county in 2008 and province in 19782007) and the parameter, respectively; $A$ is the activity data; $\mathrm{EF}$ is the region-specific emission factor $(\mathrm{EF})$; $\mathrm{RP}_{n i j m}$ represents a region-specific emission controlling parameter $m$ for activity data or $\mathrm{EF} ; f(\cdot)$ represents a function whose shape depends on the source type, which responds to $\mathrm{RP}_{\text {nijm }}$ and $C$; and $C$ stands for a coefficient. More detailed descriptions of the equations used for each source (Sect. S1), the activity data, the RPs, and the EFs (Sect. S2) can be found in the Supplement and are briefly summarized below.

\subsection{Data sources}

In this paper, county-level data for the annual quantities of synthetic fertilizer (5 types), livestock ( 8 types), crop (17 types), and rural population in 2008 were derived for 2376 counties from 329 municipal statistical registers in Mainland China, Hong Kong, Macau, and Taiwan (Hong Kong and Macau primarily have no agriculture, and thus all of their activity data equal zero). Annual above-province-level data for mainland China from 1978 to 2008 were obtained from the China Agriculture Yearbook (NBSC, 2009a) and the China Compendium of Statistics (NBSC, 2009b). Taiwanese data for 1991 to 2008 were collected from the Yearly Report of Taiwan's Agriculture (COA, 1992-2009). We obtained the 2008 unavailable fertilizer, crop, and livestock data for 332 counties in Mainland China and Taiwanese annual aboveprovince-level data for 1978-1990 based on temporal interpolation (Zhou et al., 2014). We disaggregated these activity data into $1 \times 1 \mathrm{~km}$ maps based on China's land use pattern to determine their spatial distribution. In addition, regarding activity data collected in international statistics databases for 2008, the synthetic fertilizers data were obtained from the IFA (http://www.fertilizer.org/), the rural population data were obtained from the World Bank (http://data.worldbank. org/), and the crop and livestock data were obtained from the FAO (http://faostat.fao.org/). The meteorological data for Mainland China were provided by the China Meteorological Data Sharing Service System (http://cdc.nmic.cn/home.do), and the Taiwanese meteorological data were provided by the Central Weather Bureau (http://www.cwb.gov.tw). Complementary gridded activity data include soil $\mathrm{pH}(1 \times 1 \mathrm{~km})$ (the Harmonized World Soil Database v1.2, https://daac.ornl.gov/ SOILS/guides/HWSD.html) and the secondary classification of land-use data $(1 \times 1 \mathrm{~km})(\mathrm{J}$. Y. Liu et al., 2010).

\subsection{EFs for $\mathrm{NH}_{3}$}

The EFs reported in the literature are associated with large uncertainty because of differences in ambient temperatures, planting practices, soil properties, and other crucial influential factors. In this paper, for synthetic fertilizer sources, a previously developed EF correction model was used. Because direct measurements of EFs are limited in number, the EFs were adjusted for soil $\mathrm{pH}$, fertilization method, application rate, precipitation and local temperature conditions to establish their spatial and temporal variations (i.e., the county or provincial level; monthly emissions) according to the topdown NARSES model (Webb et al., 2006) (for detailed information, see Xu et al., 2015). For livestock manure spreading sources, the original $\mathrm{NH}_{3} \mathrm{EFs}$ compiled to develop the bottom-up RAINS model were found in the EEA's inventory guidebook (EEA, 2009). However, the values for regionspecific $\mathrm{N}$ excretion in livestock manure management and the feeding days for livestock species/categories are based on published measurements for China and the results for the Livestock Manure Sector in the National Pollution Source Survey Database (NPSS) (Huang et al., 2012; MEP, 2008; SCC, 2013). Although the age and growth stage of livestock are likely to cause a certain degree of variation in the quantity of fecal excretion, this effect is only reflected by specific parameters (i.e., some form of dietary manipulation) on the farm scale (Ross et al., 2002). The activity levels and the EFs of the national- or regional-scale emission inventories do not distinguish according to the factors included in this study because EFs are restricted by activity level, i.e., animal industry statistical data. In addition, although Chinese statistics can be approximate, theoretically, they can be refined, as a number of inventories that have previously considered these factors have attempted (Huang et al., 2012). However, Chinese statistics currently contribute little to emissions inventories because of a lack of functionality and practical significance. It was assumed that the number of livestock is the same during each month of the year. The proportion of livestock EFs for different seasons, which were used to establish the annual livestock EFs, was derived from Huang et al. (2012). Hutchings et al. (2001) reported that the EFs for the same season of different months are equivalent and the different seasons of the same year change differently (Huang et al., 2012; Hutchings et al., 2001). These principles were applied in this study. Regarding the remaining sources, a literature review was aimed at collecting relevant EFs, whereby the arithmetic mean of different experiments was used. Additionally, we performed only regional correction for activity data when calculating the $\mathrm{NH}_{3}$ emission of cake fertilizers and straw returning. The emissions from these sources were equally divided over 12 months because of their smaller application and EFs. All of the EFs and parameters used in this inventory are listed in Tables S1 and S2 in the Supplement. 


\subsection{Uncertainty analysis}

A Monte Carlo simulation that consisted of 10000 calculations of the $\mathrm{NH}_{3}$ emission inventory was run to characterize the uncertainty caused by the variations in the activity data, the EFs, and related parameters. The coefficient of variation (CV) of each activity data is assumed to be equal to the absolute value of the average difference between a given data set for China used to determine CAF_NH $\mathrm{NH}_{3}$ and a default global data set (e.g., IFA, FAO, World Bank) for 2008. In addition, the CV of each activity data in 1978-2007 is assumed to be equal to the CVs of the 2008 data based on expert judgments. The $\mathrm{CV}$ values for sugarcane, highland barley, alfalfa, peanuts, other oil crops, other beans, and other tubers were set at 0.2 because they are absent from the global data sets (Zhou et al., 2014). The CV values for the EFs and related parameters were based on values found in the literature (Wang et al., 2012; Huang et al., 2012; Zhou et al., 2014; Xu et al., 2015). For activity data, uniform distributions were assumed. Normal distributions were adopted for the EFs and other parameters. The precise $\mathrm{CV}$ values are summarized in Table S3. Medians and the $R_{50}$ (difference between the 75th and 25th quartiles) were aimed at estimating the emissions and representing the uncertainties.

\section{Results}

\section{1 $\mathrm{NH}_{3}$ emissions in China in 2008}

The total $\mathrm{NH}_{3}$ emissions ( $\left.E_{\text {total }}\right)$ from CAF for 2008 were estimated as $8.4 \mathrm{TgNH}_{3} \mathrm{yr}^{-1}$ (median, 6.6-9.8 $\mathrm{Tg}$ as $R_{50}$ ), and the contribution of synthetic fertilizer application, livestock manure spreading, rural excrement, cake fertilizers, and straw returning were $3.3,3.8,0.7,0.3$, and $0.3 \mathrm{Tg}$, respectively. Detailed information on the contribution of each source to $E_{\text {total }}$ from CAF for 2008 is presented in Fig. 1. Regarding the synthetic fertilizer contribution, 1.9, 1.3, 0.02, 0.003 , and $0.05 \mathrm{Tg}$ could be attributed to ammonium bicarbonate $(\mathrm{ABC})$, urea, ammonium nitrate $(\mathrm{AN})$, ammonium sulfate (AS) and others, respectively. Among the various sources of livestock manure (Fig. S1), cattle were the largest emitter $(30.2 \%)$, followed by pigs $(28.9 \%)$, poultry $(26.2 \%)$, and dairy cattle (7.9\%). Rural excrement $(8.5 \%)$, cake fertilizer $(3.2 \%)$, and straw returning $(3.9 \%)$ were of less importance but non-negligible.

\subsection{Spatial and temporal distribution}

Figure 2 shows the $1 \mathrm{~km} \times 1 \mathrm{~km}$ and county-level geographic distributions of $\mathrm{NH}_{3}$ emissions in 2378 counties for 2008. The mean per-unit cultivated area $\mathrm{NH}_{3}$ emission was $5.9 \mathrm{tNH}_{3} \mathrm{~km}^{-2} \mathrm{yr}^{-1}$. Using county-level data to create this $\mathrm{NH}_{3}$ emissions map reveals the strong spatial association of the emissions with the distribution of arable land. The average emission density (per-unit cultivated area $\mathrm{NH}_{3}$ emis-

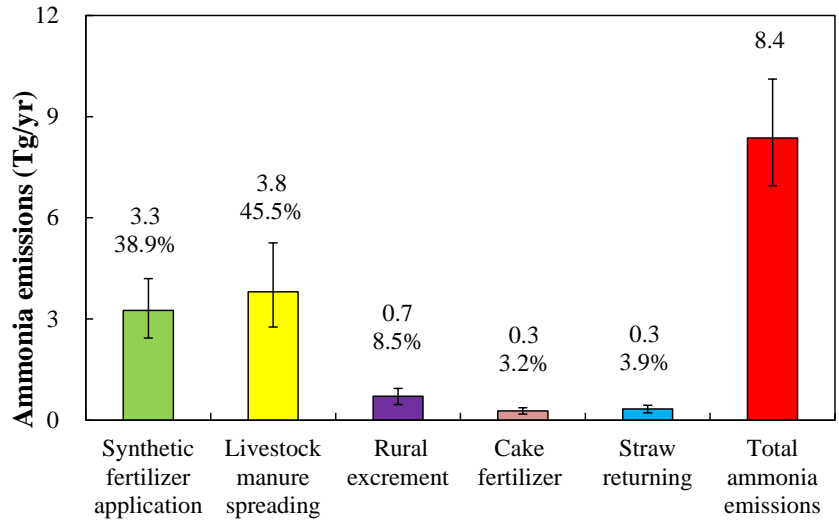

Figure 1. $\mathrm{NH}_{3}$ emissions from $\mathrm{CAF}$ for 2008 by source, and the associated uncertainties.

sion) over western, central, and eastern China is 4.7, 6.4 and $6.5 \mathrm{tNH}_{3} \mathrm{~km}^{-2} \mathrm{yr}^{-1}$, respectively. The three regions are defined in Fig. S2. Eastern China $36.7 \%$ of China's cultivated area) was the largest contributor of $\mathrm{NH}_{3}$ emissions and responsible for approximately $41.6 \%$ of the total. In central China, synthetic fertilizer was the largest contributor $(44.4 \%)$. This contribution was substantially higher than that of western $(34.0 \%)$ and eastern (36.3\%) China. However, the contribution of livestock manure spreading $(37.6 \%)$ in central China was substantially less than in western $(50.3 \%)$ and eastern $(50.2 \%)$ China. In addition, high emission densities were presented in the North China Plain, the Northeast Plain, the Huaihe River Basin, the Lianghu Plain, the Sichuan Basin, the Tarim Basin, and the Weihe Plain. Most of China's grain and livestock production is concentrated in these areas. High $\mathrm{NH}_{3}$ emission densities were also found in western China, such as Tibet, Sichuan, and Qinghai, where livestock is raised on a large scale and less cropland exists. We compared our results with the global $\mathrm{NH}_{3}$ column distribution using satellite monitoring from the Infrared Atmospheric Sounding Interferometer (IASI) (Clarisse et al., 2009; Van Damme et al., 2014). Several emissions hotspots are observed in the Tarim basin, the North China Plain, and western Heilongjiang province and Jilin province by the IASI sensor, emission density is $4.2,7.4,5.2$, and $9.6 \mathrm{tNH}_{3} \mathrm{~km}^{-2} \mathrm{yr}^{-1}$, respectively. This result demonstrated excellent qualitative consistency with our estimated emissions. However, the higher emission areas were not observed by satellite monitoring because of clouds, water vapor, the surface temperature, high $\mathrm{SO}_{2}$ emissions (Kharol et al., 2013; Wang et al., 2013; Garcia et al., 2008), land surface variation, and the retrieval methods of $\mathrm{NH}_{3}$ total columns (Xu et al., 2015). Higher cloud cover and precipitation could generate some uncertainties in the Sichuan Basin and Lianghu Plain. Additionally, $\mathrm{NH}_{3}$ concentration distribution might not be always in agreement with emission pattern due to its high reactive ability, solubility, and its short-lived duration in the atmo- 

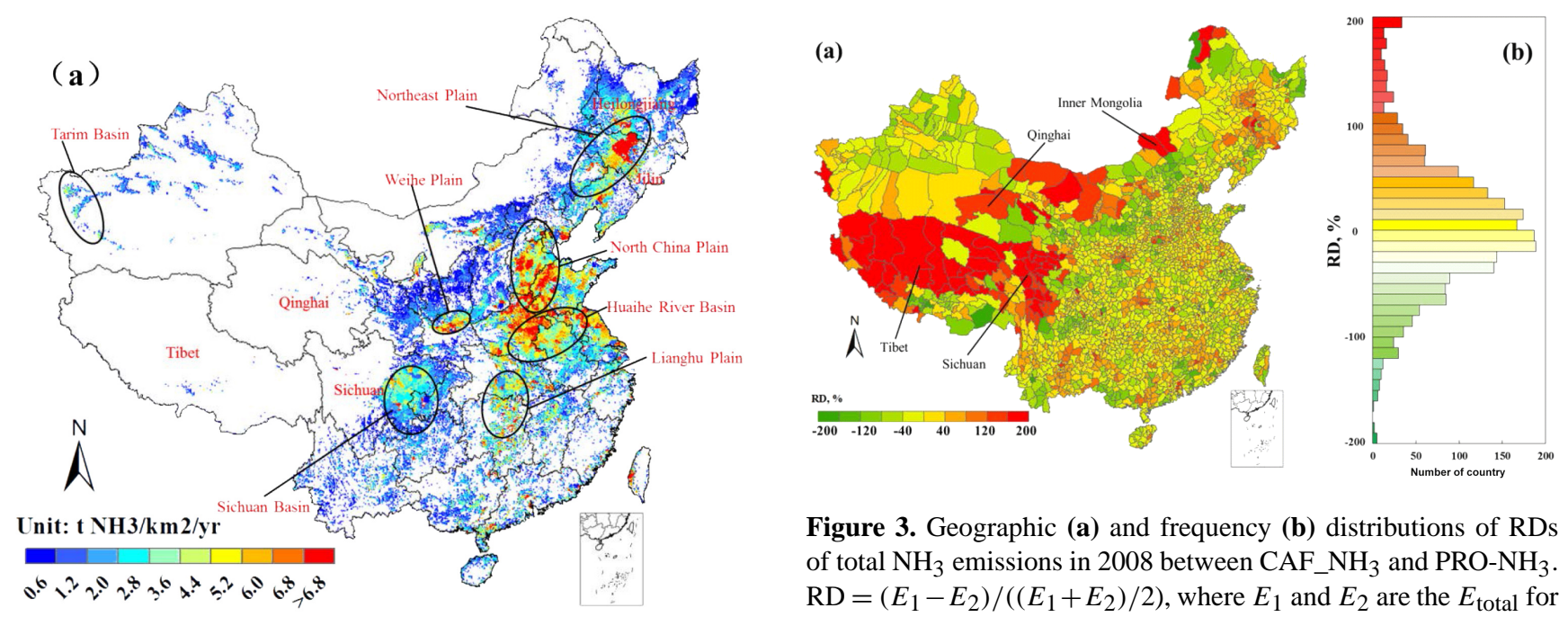

Figure 3. Geographic (a) and frequency (b) distributions of RDs of total $\mathrm{NH}_{3}$ emissions in 2008 between CAF_NH $\mathrm{NH}_{3}$ and PRO-NH 3 . $\mathrm{RD}=\left(E_{1}-E_{2}\right) /\left(\left(E_{1}+E_{2}\right) / 2\right)$, where $E_{1}$ and $E_{2}$ are the $E_{\text {total }}$ for agricultural fertilizer of the counties for $\mathrm{CAF}_{-} \mathrm{NH}_{3}$ and for PRO$\mathrm{NH}_{3}$ for each county, respectively. A negative (positive) RD suggests an overestimation (underestimation) of a county's emissions by utilizing the provincial disaggregation approach $\left(\mathrm{PRO}-\mathrm{NH}_{3}\right)$.

(Wang et al., 2012), where $E_{1}$ and $E_{2}$ are the $E_{\text {total }}$ for agricultural fertilizer of the counties for $\mathrm{CAF}_{-} \mathrm{NH}_{3}$ and for PRO$\mathrm{NH}_{3}$ for each county, respectively. Figure 3 shows all counties' frequency and spatial distributions of the RDs. The spatial bias of the provincial disaggregation increases as the absolute RDs. A negative (positive) RD suggests an overestimation (underestimation) of a county's emissions by utilizing the provincial disaggregation approach $\left(\mathrm{PRO}-\mathrm{NH}_{3}\right)$. The mean absolute RD was $48.7 \%$ for all counties. In $37 \%$ of the countries, the absolute RDs were found higher than $50 \%$. In addition, the $\mathrm{PRO}-\mathrm{NH}_{3}$ emission pattern is lowly correlated with the CAF-NH 3 pattern $(R=0.49, p<0.01)$. These results indicate that spatial bias can be substantially reduced using the county-level activity data and that provincial disaggregation using regression models cannot determine the county-scale structure of the spatial distribution of activity data within provinces. Large RDs were often observed in provinces and regions in which the development status significantly varies, such as Sichuan, Qinghai, Inner Mongolia, and Tibet.

By comparing nitrogen fertilizer, compound fertilizer, rural population, rice, wheat, maize, cattle, sheep, and pigs activity data (1978-2007) which are the major $\mathrm{NH}_{3}$ emission sources in this study from NBSC provincial statistics (sums of the provincial data), IFA and FAO (national data), it was found that $64.8 \%$ IFA and FAO statistics underestimated the above activity data from 1978 to 2007 because of the difference in statistical criteria, especially in rural population and sheep which attained 100 and $80.0 \%$ respectively (Fig. S3). The possible underestimation of national emission statistics has been demonstrated by $\mathrm{NH}_{3}$ emission trends based on the per capita livestock that can cover all the $\mathrm{NH}_{3}$ emission during the whole lifespan of livestock in Gu et al. (2012), and 


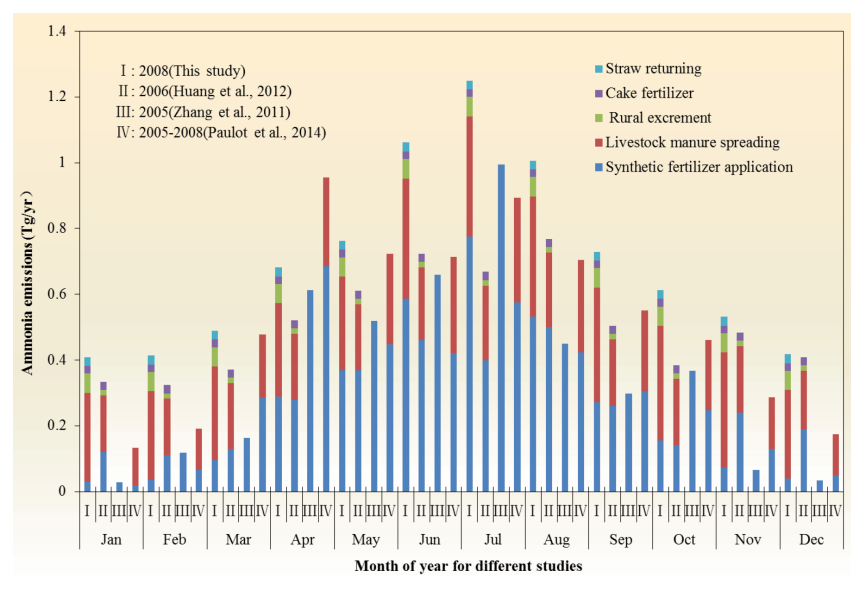

Figure 4. Monthly $\mathrm{NH}_{3}$ emissions in 2008 and compared with earlier studies.

this fact may support our conclusion. Considering the information presented here and the limit of county-level activity data availability in 1978-2007, province-level activity data from 1978 to 2007 were used in our study in order to develop high-resolution inventory.

Figure 4 shows the monthly $\mathrm{NH}_{3}$ emissions in 2008 from various sources, which are generally in agreement with the local climate, planting time, and cultivation practices. Higher emissions occurred during the summer (June to August) and accounted for $39.7 \%$ of the annual total emissions. These higher emissions are virtually identical with several in situ data sets (Ianniello et al., 2010; Meng et al., 2011). In addition, the seasonality of emissions from IASI and Tropospheric Emission Spectrometer (TES) satellite observations demonstrated excellent consistency with the temporal distribution of our inventory which is a summer maximum of $\mathrm{NH}_{3}$ emissions in China (Shephard et al., 2011; Van Damme et al., 2015). The peak value was found for July $\left(1.2 \mathrm{TgNH}_{3} \mathrm{yr}^{-1}\right)$. This value was approximately 3.1 times larger than the smallest value (January). Regarding synthetic fertilizer sources, $\mathrm{NH}_{3}$ emissions significantly increased in April, peaked in July, and then decreased. This pattern could be partly attributed to an increased application of synthetic fertilizer and higher temperatures. In China, winter wheat and oilseed rape are typically seeded in late September and early October with the base fertilizer application. The basal dressing and topdressing of summer maize occur in June and August. In addition, early rice sowing, late rice sowing and transplanting typically occur in April and July and are accompanied by base fertilization. For these crops, topdressing is performed in late June and late September, respectively. A total of 50$80 \%$ of the synthetic fertilizer is applied at or around planting (Zhang et al., 2011). The largest livestock manure spreading emissions also occurred in summer and accounted for nearly $28.8 \%$ of livestock manure spreading emissions. This result might be explained by larger EFs related to the sub- stantial increase in ambient temperature and little variation in the livestock population among the different months (Huang et al., 2012). The $\mathrm{NH}_{3}$ emissions in winter (December to February) were lower due to the relatively lower temperature and infrequent agricultural activities. The spatial distributions of CAF $\mathrm{NH}_{3}$ for January, April, July, and October are shown in Fig. S4. In western China, rural excrement's monthly contribution proportions were higher than in eastern China, particularly during winter (1.6 times); in central China, synthetic fertilizer's monthly contribution proportions began to exceed livestock manure in April (Fig. S5); however this condition occurred in May in eastern and western China because of temperature that rebounded significantly. In addition, $\mathrm{NH}_{3}$ emissions in central China (i.e., in Guangdong, Guangxi and Hainan) were typically more stable than in eastern China (i.e., in Jilin, Liaoning, and Heilongjiang) because of less dramatic temperature fluctuations and less intensive agricultural activities.

\subsection{Historical time trend for $\mathrm{NH}_{3}$ emissions in China}

Annual CAF $\mathrm{NH}_{3}$ emissions were estimated based on the activity data, the EFs, and related parameters as described in the Methodology section for 1978 to 2008. Figure 5 shows the annual variations in $E_{\text {total }}$ and the distributions of each sector during the study years. The emissions increased from 3.2 to $8.4 \mathrm{Tg}$ (2.6 times) during the period 1978-2008. Fertilizer has been promoted as an important means to improve crop yields because the overall grain response to fertilizer and to technological and institutional changes is viewed as crucial to Chinese agricultural production (Wang et al., 1996). In addition, because of the initiation of reform and opening-up in 1978, the government has implemented a subsidy policy with respect to fertilizer and urged farmers to apply additional fertilizer to increase grain yields. From 1978 to $2008, E_{\text {total }}$ fluctuated, with peaks in 1987, 1996 and 2005. The $\mathrm{NH}_{3}$ emissions growth rates in 1978-1987 and 1988-1996 were 41.7 and $51.3 \%$, respectively, primarily as a result of the improvement of the unified food price in 1979 to increase the enthusiasm of farmers after the establishment of the Householder's Responsibility System. The system enhanced China's agricultural intensification degree and continuously increased the intensity of fertilizer use. In 1988, $\mathrm{NH}_{3}$ emissions appeared to decrease. The primary reason for this decrease was the shortage and/or inflated price of supplies and equipment required for agricultural production, particularly the substantially higher prices of synthetic fertilizer and fodder, which increased agricultural production costs and thus affected production output. In addition, a severe drought occurred during the entire year, which seriously affected agricultural production (Ma and Zhao, 1989). In 1997-2005, the $\mathrm{NH}_{3}$ emission growth rate was $17.4 \%$. This rate reflects a steady growth trend although one that was slower than that of the first two periods because following the grain yield peak in 1998 (512.3 Tg, NBSC, 2009a) grain prices decreased as a result 


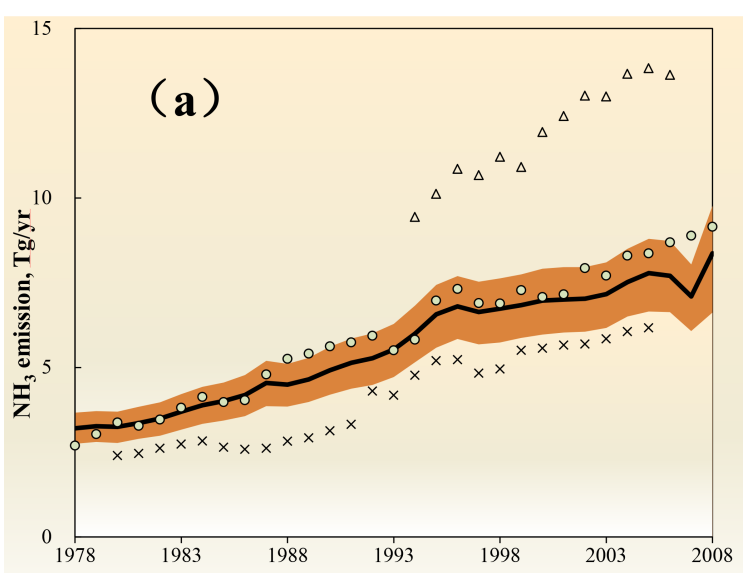

\begin{tabular}{|ll|}
\hline - This study $(\mathrm{SF}+\mathrm{LS}+\mathrm{RE}+\mathrm{CF}+\mathrm{SR})$ & $\circ$ EDGAR v4.2 (SF + LS) \\
$\times \quad$ Wang et al $(\mathrm{SF}+\mathrm{LS}+\mathrm{RE})$ & $\triangle$ Dong et al $(\mathrm{SF}+\mathrm{LS}+\mathrm{RE})$ \\
\hline
\end{tabular}

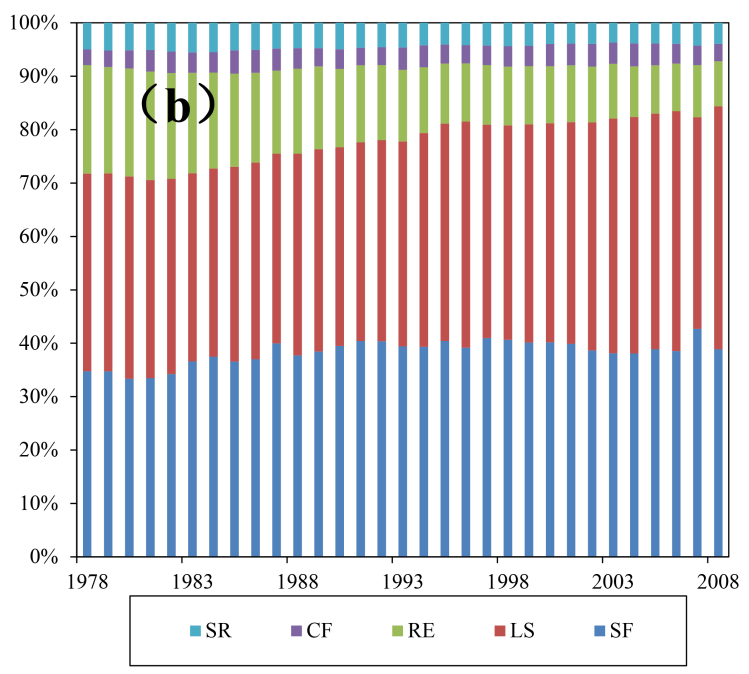

Figure 5. Temporal trend for agricultural fertilizer $\mathrm{NH}_{3}$ emissions for China (a) and sector contributions between 1978 and 2008 (b). The emission estimate and the uncertainty are provided as a median value (black curve) and the $R_{50}$ (shaded area, for total emissions) derived from a Monte Carlo simulation. Note: SF refers to synthetic fertilizer application; LS refers to livestock manure spreading; RE refers to rural excrement; $\mathrm{CF}$ refers to cake fertilizer; SR refers to straw returning.

of oversupply. These events sharply reduced the enthusiasm of farmers engaged in agricultural production. In addition, with China's accession to the World Trade Organization in 2001, lower overseas grain prices restrained the increase of domestic grain prices, which encouraged the rural population transfer to non-agricultural production. The national government did not recognize the problem's severity until the end of 2003 and then issued a series of favorable and preferential agricultural policies, including the repeal of the agriculture tax. This policy approach reversed the damaging decline of crop yields. However, influenced by the Asian financial crisis and El Nino, in 1997, emissions decreased. Since 2005, grain yields have continuously increased, and the quantity of synthetic fertilizer applied has decreased overall as a result of the dissemination of new technologies for soil testing and fertilizer formulation. $E_{\text {total }}$ decreased in 2007 and then increased. Natural disasters and livestock and poultry disease caused a marked decline in livestock breeding stock, which is the primary reason for the sudden decrease in $\mathrm{NH}_{3}$ emissions in 2007. That is, livestock manure emissions decreased $18.8 \%$ compared with 2006.

Regarding the contribution by each sector in China, the contribution of livestock manure spreading increased from $37.0 \%$ in 1978 to $45.5 \%$ in 2008 because fertilization practices changed from organic to inorganic fertilizer and then to a combination of these types. To encourage farmers to use more organic fertilizer and to spur the development of organic fertilizer resources across the country, in 1988, the Chinese State Council published "With respect to instruction of valuing and reinforcing organic fertilizer" (Chinese State Council, 1998.). Subsequently, farmers realized that organic fertilizer could play a significant role in water conservation, soil fertilization, and soil improvement. In addition, livestock and poultry breeding techniques were improved as a result of the rapid increase in egg, milk, and meat consumption. The contribution of livestock manure spreading (from pigs, poultry, and dairy cattle) has been increasing during the past 31 years, others (from cattle, sheep, horses, donkeys, and mules) have observed the opposite trend. However, the largest contributors are cattle and pigs (46.6 and $23.3 \%$, respectively, on average) (Table S4). The average contribution of synthetic fertilizer to $E_{\text {total }}$ is approximately $38.3 \%$ during the past 31 years, and the minimum and maximum is 33.4 and $42.7 \%$ respectively. Generally, synthetic fertilizer application exhibits a strong positive correlation with crop yields $\left(R^{2}=0.89\right)$ (Fig. S6). In addition, because of the growth effect of synthetic fertilizer in agriculture, the high demand for synthetic fertilizer will not change. Synthetic fertilizer application will continue to increase as the optimization of the domestic agricultural planting structure and the cash crop planting area increase. The contribution of the rural excrement sector substantially decreased from $20.3 \%$ in 1978 to $8.5 \%$ in 2008 as a result of the decline in China's rural population that accompanied rapid urbanization. The contributions of cake fertilizer and straw returning were small and remained stable during the study period. Their average contributions were approximately 3.8 and $4.5 \%$, respectively. Collectively, these findings support the hypothesis that in addition to the limitation of climate conditions, agricultural production suffered as a consequence of the co-ordination and control of the country's agricultural policy, which directly affected the $\mathrm{NH}_{3}$ emissions of fertilizers used in agricultural production. That is, to a certain extent, the $\mathrm{NH}_{3}$ emissions attributable to agricultural fertilizer reflect the country's agricultural policy. Overall, our findings are in substantial qualitative agreement with the analysis of China's fertilizer policies by $\mathrm{Li}$ et al $(\mathrm{Li}$ et al., 2013). 
Table 1. Total $\mathrm{NH}_{3}$ emissions $\left(\mathrm{TgNH}_{3} \mathrm{yr}^{-1}\right)$; source profile by sector after 2004 and their comparisons with previous studies. Note: SF refers to synthetic fertilizer application; LS refers to livestock manure spreading; RE refers to rural excrement; CF refers to cake fertilizer; SR refers to straw returning. 6.2 represents the sum of LS and RE in Cao et al. (2010); 2.8 represents the sum of LS and RE in Wang et al. (2009).

\begin{tabular}{lllllllrr}
\hline References & Base year & EFs & SF & LS & RE & CF & SR & Total \\
\hline This study & 2008 & Correction EFs & 3.3 & 3.8 & 0.7 & 0.3 & 0.3 & 8.4 \\
Paulot et al. (2014) & $2005-2008$ & Region-specific EFs & 3.6 & 2.6 & & & & 6.2 \\
EDGAR (2013) & 2008 & IPCC & 8.1 & 1.1 & & & 9.2 \\
Cao et al. (2010) & 2007 & EEA & 3.6 & \multicolumn{2}{c}{6.2} & & & 9.8 \\
Huang et al. (2012) & 2006 & Correction EFs & 3.2 & 2.4 & 0.2 & 0.3 & 0.3 & 6.4 \\
Dong et al. (2010) & 2006 & EEA & 8.7 & 4.3 & 0.7 & & & 13.7 \\
Wang et al. (2009) & 2005 & Region-specific EFs & 3.5 & 2.8 & & & 6.3 \\
Zhang et al. (2011) & 2005 & Correction EFs & 4.3 & & & & 4.3 \\
Li and Li (2012) & 2004 & Region-specific EFs & 1.8 & 3.7 & 1.7 & & & 7.2 \\
\hline
\end{tabular}

\section{Discussion}

\subsection{Differences with previous $\mathrm{NH}_{3}$ emissions inventories}

Table 1 presents a comparison of the $2004-2008 \mathrm{NH}_{3}$ emission inventories for China of this study with other inventories that investigated the same emission sources. Our estimate is $22.8 \%$ less than that of EDGAR v.4.2 (2013), $20.4 \%$ less than that of Cao et al. (2010), and $43.1 \%$ less than that of Dong et al. (2010). These differences primarily result from differences in synthetic fertilizer emissions. The previous estimates employed uniform EFs for the entire country, which were derived from foreign expert evaluations or European rather than local data. However, despite using corrected EFs (Zhang et al., 2011), our estimate is $23.3 \%$ lower than that of Zhang et al. (2011). This difference can be partly attributed to the choice of parameters used in the EF corrections. Our estimate is completely based on local measurements, whereas the results of Zhang et al. (2011) were primarily based on measurements performed in Europe. Our estimate is $23.8 \%$ higher than that of Huang et al. (2012), $14.5 \%$ higher than that of Paulot et al. (2014), 19.2\% higher than that of Wang et al. (2009), and $7.7 \%$ higher than that of $\mathrm{Li}$ and $\mathrm{Li}$ (2012). These differences are explained by the differences in base year and by the use of regional EFs as well as local and high-resolution activity data. The annual $\mathrm{NH}_{3}$ emissions calculated in this study were compared with previous estimates (Wang et al., 2009; Dong et al., 2010), and the results are shown in Fig. 5a. A year-by-year comparison of the findings of EDGAR v.4.2 (2013) or Wang et al. (2009) with the findings of this study indicates that the growth trends compare well for 1980-2005. Our estimates for 1994 to 2006 are approximately 1.8 times lower than those of Dong et al. (2010) for each year. We compared our monthly variation of synthetic fertilizer application to the findings of Paulot et al. (2014), Huang et al. (2012) and Zhang et al. (2011). Our estimates agree well with the above three inventories for the monthly variation tendency. However, in our study and that of Zhang et al. (2011), emissions peaked in July, whereas in Huang et al. (2012), the emissions peaked in August, and the maximum emission occurred during summer, this phenomenon could be primarily attributed to the local climate conditions, which affected the EFs for the base year, but in Paulot et al. (2014), the emissions peaked in April because erroneous planting dates were used in the crop model such as the winter wheat-summer corn rotation, where corn was sown in June instead of in April in China (Huang et al. 2012). This study assumes that $60 \%$ of the synthetic fertilizer is used in planting, $20 \%$ in growth and $20 \%$ in harvest. Regarding livestock manure, our estimates are approximately 1.6 times larger than the monthly results of Huang et al. because of different base years, EF selection and differences in livestock population. In our study, emissions for livestock manure spreading peaked in June-August, which was similar to the corresponding findings of Paulot et al. (2014), whereas the monthly emission in winter in our study was nearly 2.2fold higher than in Paulot et al. (2014). The reason is that in Paulot et al. (2014) the timing of livestock manure spreading is presumed to be identical with synthetic fertilizer application and the crops hardly need synthetic fertilizer application in winter, however, in this study the number of livestock is the same during each month of the year and the EFs for the same season of different months are equivalent.

\subsection{Impacts of $\mathrm{NH}_{3}$ emissions on urban air pollution}

A key research and policy question is how $\mathrm{NH}_{3}$ emissions affect China's urban air pollution (in terms of $\mathrm{PM}_{2.5}$ and its precursors, e.g., $\mathrm{NO}_{x}, \mathrm{SO}_{2}$ and $\mathrm{NH}_{3}$ ). Because China is a large agricultural country, CAF is the nation's largest emitter of $\mathrm{NH}_{3}$. However, China is in the midst of an urban expansion necessary to becoming an economic superpower. The nation's urbanization rate (the urbanization rate equals the proportion of the urban population and the total population, http://www.stats.gov.cn/) rapidly increased from 
$17.9 \%$ in 1978 to $47.0 \%$ in 2008 (NBSC, 2009a). In addition to urbanization, the difference between $\mathrm{CAF} \mathrm{NH}$ emissions and $\mathrm{NO}_{x}$ and $\mathrm{SO}_{2}$ emissions from fossil-fuel combustion is being effaced by the development of intensive agricultural and livestock production in marginal zones between rural and urban areas, which results in $\mathrm{PM}_{2.5}$ that exacerbates urban air quality because the pollutants react more easily (Gu et al., 2014). Additionally, the high $\mathrm{PM}_{2.5}$ levels of 2014 in China occurred in areas that overlap with agricultural areas (Fig. S7). Apparently, the $\mathrm{CAF} \mathrm{NH}_{3}$ emissions cause urban air pollution by aerial transformation. Using a response surface modeling technique, Wang et al. (2011) revealed that approximately $50-60 \%$ of the increases in $\mathrm{NO}_{3}^{-}$ and $\mathrm{SO}_{4}^{2-}$ aerosol concentrations were caused by the $90 \%$ increase in $\mathrm{NH}_{3}$ emissions from 1990-2005 in East China. Wang et al. (2013) utilized GEOS-Chem to examine the impact of precursors of changes in anthropogenic emissions on the change in sulfate-nitrate-ammonium aerosols over China during 2000-2015, and found that the advantage of $\mathrm{SO}_{2}$ reduction would be totally neutralized if $\mathrm{NH}_{3}$ emissions increased by $16 \%$ from 2006 to 2015 , as anticipated based on China's recent growth rate. Therefore, to decrease $\mathrm{PM}_{2.5}$ concentrations and improve urban air quality in China, a more effective approach would be to simultaneously decrease $\mathrm{NO}_{x}, \mathrm{SO}_{2}$, and $\mathrm{NH}_{3}$ emissions. However, the determination of the degree to which $\mathrm{CAF} \mathrm{NH}_{3}$ contributes to the urban $\mathrm{PM}_{2.5}$ concentration is a topic for future research. Our high-resolution inventory can be applied to simulate atmospheric aerosol formation in air quality models with a bidirectional $\mathrm{NH}_{3}$ exchange module, and then explore the effects of $\mathrm{NH}_{3}$ emissions on China's urban air pollution.

\section{Implications for $\mathrm{NH}_{3}$ emissions}

With the local high-resolution data, spatially and temporally precise $\mathrm{EF}_{\mathrm{NH}_{3}}$ and related parameters, times series of CAF_NH ${ }_{3}$ emissions were developed, which provide the high-resolution maps of $\mathrm{NH}_{3}$ emission densities, the source apportionment, and the spatial and temporal pattern for 2008 as well as a historical time trend analysis of total $\mathrm{NH}_{3}$ emissions from 1978 to 2008 . Additionally, we could distinguish $\mathrm{NH}_{3}$ emissions hotspots and their spatial and temporal variations as well as identify the influence of national agricultural policy changes on $\mathrm{NH}_{3}$ emissions because the initiation of reform and opening-up. Fortunately, the rate of $\mathrm{NH}_{3}$ emissions during the last decade has increased slowly compared with 1978-1996. As a result of their high volatility, urea and $\mathrm{ABC}$ have been gradually replaced by compound nitrogenphosphorous-potassium and organic fertilizers in the wake of the country attaching greater importance to the food security problem. Although an increasing portion of the rural population has moved to cities in the current period of rapid urbanization, a large rural population will continue to exist in the next decades (Wang et al., 2012). Agricultural fertilizer will continue to be required to meet the increasing demand for food, and fertilizer application technology will slowly improve (Sutton et al., 2011). To decrease the $\mathrm{NH}_{3}$ emissions from agricultural fertilizers, it is necessary to enhance the efficient use of agricultural fertilizer, reduce the intensity of agricultural fertilizer use, improve environmental factors and accelerate abatement strategy development. Liu et al. (2013) and J. G. Liu et al. (2010) noted that the accuracy as well as the temporal and spatial resolution of $\mathrm{CAF}_{-} \mathrm{NH}_{3}$ inventories is essential to better quantify atmospheric $\mathrm{N}$ deposition and more accurately assess nitrogen flows in cropland (Liu et al., 2013; J. G. Liu et al., 2010). Nevertheless, several uncertainties still exist in our inventory especially in the emissions from synthetic fertilizer application and livestock manure spreading due to the exceedingly high values and large amount of parameters related to the emission factors adjustment. It has been demonstrated that a dependable data-driven approach and local experiments or process-based models can substantially help increase the spatial and temporal resolution and decrease the uncertainties of emissions inventories. Therefore, they should be implemented in future research.

\section{The Supplement related to this article is available online at doi:10.5194/acp-16-1207-2016-supplement.}

Acknowledgements. This work was financially supported by the International Science \& Technology Cooperation Program of China (2012DFG92020).

Edited by: G. Frost

\section{References}

Bash, J. O., Cooter, E. J., Dennis, R. L., Walker, J. T., and Pleim, J. E.: Evaluation of a regional air-quality model with bidirectional $\mathrm{NH}_{3}$ exchange coupled to an agroecosystem model, Biogeosciences, 10, 1635-1645, doi:10.5194/bg-10-1635-2013, 2013.

Bouwman, A. F., Lee, D. S., Asman, W. A. H., Dentener, F. J., VanderHoek, K. W., and Olivier, J. G. J.: A global high-resolution emission inventory for ammonia, Global. Biogeochem. Cy., 11, 561-587, 1997.

Cao, G. L., An, X. Q., Zhou, C. H., Ren, Y. Q., and Tu, J.: Emission inventory of air pollutants in China, China Environmental Science 30, 900-906, 2010 (in Chinese).

Chinese State Council: With respect to instruction of valuing and reinforcing organic fertilizer, Gazette of the State Council of the People's Republic of China, 27, 889-891, 1988 (in Chinese).

Clarisse, L., Clerbaux, C., Dentener, F., Hurtmans, D., and Coheur, P. F.: Global ammonia distribution derived from infrared satellite observations, Nat. Geosci., 2, 479-483, 2009.

Cooter, E. J., Bash, J. O., Walker, J. T., Jones, M. R., and Robarge, W.: Estimation of $\mathrm{NH}_{3}$ bi-directional flux from 
managed agricultural soils, Atmos. Environ., 44, 2107-2115, doi:10.1016/j.atmosenv.2010.02.044, 2010.

Council of Agriculture (COA): Yearly Report of Taiwan's Agriculture Department of Agriculture and Forestry of Taiwan Provincial Government: Taipei, Taiwan, 1991-2008.

Cui, Z. L., Wang, G. L., Yue, S. C., Wu, L., Zhang, W. F., Zhang, F. S., and Chen, X. P.: Closing the N-Use Efficiency Gap to Achieve Food and Environmental Security, Environ. Sci. Technol., 48, 5780-5787, 2014.

Dong, W. X., Xing, J., and Wang, S. X.: Temporal and Spatial Distribution of Anthropogenic Ammonia Emissions in China: 19942006, China Environmental Science, 31, 1457-1463, 2010 (in Chinese).

Emission Database for Global Atmospheric Research (EDGAR): Global Emissions EDGAR v4.2., available at: http://edgar.jrc.ec. europa.eu/overview.php?v=42, last access: 11 November 2013.

Erisman, J. W., Galloway, J. N., Seitzinger, S., Bleeker, A., Dise, N. B., Petrescu, A. M. R., Leach, A. M., and de Vries, W.: Consequences of human modification of the global nitrogen cycle, Philos. T. Roy. Soc. B., 368, 20130116, doi:10.1098/rstb.2013.0116, 2013.

European Environment Agency (EEA): EMEP/EEA air pollutant emission inventory guidebook 2009, Tech. Rep. 9/2009, Copenhagen, 2009.

Fu, X., Wang, S. X., Ran, L. M., Pleim, J. E., Cooter, E., Bash, J. O., Benson, V., and Hao, J. M.: Estimating $\mathrm{NH}_{3}$ emissions from agricultural fertilizer application in China using the bidirectional CMAQ model coupled to an agro-ecosystem model, Atmos. Chem. Phys., 15, 6637-6649, doi:10.5194/acp-15-66372015, 2015.

Gao, B., Ju, X. T., Zhang, Q., Christie, P., and Zhang, F. S.: New estimates of direct $\mathrm{N}_{2} \mathrm{O}$ emissions from Chinese croplands from 1980 to 2007 using localized emission factors, Biogeosciences, 8, 3011-3024, doi:10.5194/bg-8-3011-2011, 2011.

Garcia, P., Benarroch, A., and Riera, J. M.: Spatial distribution of cloud cover, Int. J. Satell. Comm. N., 26, 141-155, 2008.

Gu, B. J., Ge, Y., Ren, Y., Xu, B., Luo, W. D., Jiang, H., Gu, B. H., and Chang, J.: Atmospheric Reactive Nitrogen in China: Sources, Recent Trends, and Damage Costs, Environ. Sci. Technol., 46, 9420-9427, 2012.

Gu, B. J., Sutton, M. A., Chang, S. X., Ge, Y., and Chang, J.: Agricultural ammonia emissions contribute to China's urban air pollution, Front. Ecol. Environ., 12, 265-266, 2014.

Hellsten, S., Dragosits, U., Place, C. J., Vieno, M., Dore, A. J., Misselbrook, T. H., Tang, Y. S., and Sutton, M. A.: Modelling the spatial distribution of ammonia emissions in the UK, Environ. Pollut., 154, 370-379, 2008.

Huang, X., Song, Y., Li, M. M., Li, J. F., Huo, Q., Cai, X. H., Zhu, T., Hu, M., and Zhang, H. S.: A high-resolution ammonia emission inventory in China, Global. Biogeochem. Cy., 26, GB1030, doi:10.1029/2011GB004161, 2012.

Huang, X. F., Yun, H., Gong, Z. H., Li, X., He, L., Zhang, Y. H., and $\mathrm{Hu}, \mathrm{M} .:$ Source apportionment and secondary organic aerosol estimation of $\mathrm{PM}_{2.5}$ in an urban atmosphere in China, Sci. China. Earth. Sci., 57, 1352-1362, 2014.

Hutchings, N. J., Sommer, S. G., Andersen, J. M., and Asman, W. A. H.: A detailed ammonia emission inventory for Denmark, Atmos. Environ., 35, 1959-1968, 2001.
Ianniello, A., Spataro, F., Esposito, G., Allegrini, I., Rantica, E., Ancora, M. P., Hu, M., and Zhu, T.: Occurrence of gas phase ammonia in the area of Beijing (China), Atmos. Chem. Phys., 10, 9487-9503, doi:10.5194/acp-10-9487-2010, 2010.

IPCC: 2006 IPCC Guidelines for National Greenhouse Gas Inventories, National Greenhouse Gas Inventories Programme, IGES, Japan, 2006.

Kharol, S. K., Martin, R. V., Philip, S., Vogel, S., Henze, D. K., Chen, D., Wang, Y., Zhang, Q., and Heald, C. L.: Persistent sensitivity of Asian aerosol to emissions of nitrogen oxides, Geophys. Res. Lett., 40, 1021-1026, 2013.

Kim, J. Y., Song, C. H., Ghim, Y. S., Won, J. G., Yoon, S. C., Carmichael, G. R., and Woo, J. H.: An investigation on $\mathrm{NH}_{3}$ emissions and particulate $\mathrm{NH}_{4}^{+}-\mathrm{NO}_{3}^{-}$formation in East Asia, Atmos. Environ., 40, 2139-2150, 2006.

Langridge, J. M., Lack, D., Brock, C. A., Bahreini, R., Middlebrook, A. M., Neuman, J. A., Nowak, J. B., Perring, A. E., Schwarz, J. P., Spackman, J. R., Holloway, J. S., Pollack, I. B., Ryerson, T. B., Roberts, J. M., Warneke, C., de Gouw, J. A., Trainer, M. K., and Murphy, D. M.: Evolution of aerosol properties impacting visibility and direct climate forcing in an ammonia-rich urban environment, J. Geophys. Res-Atmos., 117, D00V11, doi:10.1029/2011JD017116, 2012.

Li, X. Y. and Li, H. P.: Emission and distribution of $\mathrm{NH}_{3}$ and $\mathrm{NO}_{X}$ in China, China Environmental Science, 32, 37-42, 2012 (in Chinese).

Li, Y. X., Zhang, W. F., Ma, L., Huang, G. Q., Oenema, O., Zhang, F. S., and Dou, Z. X.: An Analysis of China's Fertilizer Policies: Impacts on the Industry, Food Security, and the Environment, J. Environ. Qual., 42, 972-981, 2013.

Liu, J. G., You, L. Z., Amini, M., Obersteiner, M., Herrero, M., Zehnder, A. J. B., and Yang, H.: A high-resolution assessment on global nitrogen flows in cropland, P. Natl. Acad. Sci. USA, 107, 8035-8040, 2010.

Liu, J. Y., Zhang, Z. X., Xu, X. L., Kuang, W. H., Zhou, W. C., Zhang, S. W., Li, R. D., Yan, C. Z., Yu, D. S., Wu, S. X., and Nan, J.: Spatial patterns and driving forces of land use change in China during the early 21 st century, J. Geogr. Sci., 20, 483-494, 2010.

Liu, X. J., Zhang, Y., Han, W. X., Tang, A. H., Shen, J. L., Cui, Z. L., Vitousek, P., Erisman, J. W., Goulding, K., Christie, P., Fangmeier, A., and Zhang, F. S.: Enhanced nitrogen deposition over China, Nature, 494, 459-462, 2013.

Ma, L., Wang, F. H., Zhang, W. F., Ma, W. Q., Velthof, G., Qin, W., Oenema, O., and Zhang, F. S.: Environmental Assessment of Management Options for Nutrient Flows in the Food Chain in China, Environ. Sci. Technol., 47, 7260-7268, 2013.

Ma, Q. Y. and Zhao, Z. G.: Weather climate characteristics in China and the main circulation characteristic of the northern hemisphere for 1988, Meteorological Monthly, 4, 33-38, 1989 (in Chinese).

Martin, S. T., Hung, H.-M., Park, R. J., Jacob, D. J., Spurr, R. J. D., Chance, K. V., and Chin, M.: Effects of the physical state of tropospheric ammonium-sulfate-nitrate particles on global aerosol direct radiative forcing, Atmos. Chem. Phys., 4, 183214, doi:10.5194/acp-4-183-2004, 2004.

Meng, Z. Y., Lin, W. L., Jiang, X. M., Yan, P., Wang, Y., Zhang, Y. M., Jia, X. F., and Yu, X. L.: Characteristics of atmospheric 
ammonia over Beijing, China, Atmos. Chem. Phys., 11, 61396151, doi:10.5194/acp-11-6139-2011, 2011.

MEP/NSB/MOA. National Pollution Source Survey Database, Beijing, 2008.

National Bureau of Statistics of China (NBSC): China Agriculture Yearbook, 1980-2009, China Statistics Press, Beijing, 2009a.

National Bureau of Statistics of China (NBSC): China Compendium of Statistics, 1949-2008, China Statistics Press, Beijing, 2009b.

Olivier, J. G. J., Bouwman, A. F., Van der Hoek, K. W., and Berdowski, J. J. M.: Global air emission inventories for anthropogenic sources of $\mathrm{NO}_{x}, \mathrm{NH}_{3}$ and $\mathrm{N}_{2} \mathrm{O}$ in 1990, Environ. Pollut., 102, 135-148, 1998.

Paulot, F., Jacob, D. J., Pinder, R. W., Bash, J. O., Travis, K., and Henze, D. K.: Ammonia emissions in the United States, European Union, and China derived by high-resolution inversion of ammonium wet deposition data: Interpretation with a new agricultural emissions inventory (MASAGE_NH 3 ), J. Geophys. ResAtmos., 119, 4343-4364, 2014.

Pinder, R. W., Adams, P. J., and Pandis, S. N.: Ammonia emission controls as a cost-effective strategy for reducing atmospheric particulate matter in the eastern United States, Environ. Sci. Technol., 41, 380-386, 2007.

Pleim, J. E., Bash, J. O., Walker, J. T., and Cooter, E. J.: Development and evaluation of an ammonia bidirectional flux parameterization for air quality models, J. Geophys. Res-Atmos., 118, 3794-3806, doi:10.1002/jgrd.50262, 2013.

Ross, C. A., Scholefield, D., and Jarvis, S. C.: A model of ammonia volatilisation from a dairy farm: an examination of abatement strategies, Nutr. Cycl. Agroecosys., 64, 273-281, 2002.

Shephard, M. W., Cady-Pereira, K. E., Luo, M., Henze, D. K., Pinder, R. W., Walker, J. T., Rinsland, C. P., Bash, J. O., Zhu, L., Payne, V. H., and Clarisse, L.: TES ammonia retrieval strategy and global observations of the spatial and seasonal variability of ammonia, Atmos. Chem. Phys., 11, 10743-10763, doi:10.5194/acp-11-10743-2011, 2011.

State Council of China (SCC): The First National Pollution Source Survey: Nutrient Loss Ratio of Agricultural Fertilizer, available at: http://cpsc.mep.gov.cn/, last access: 12 November 2013.

Streets, D. G., Bond, T. C., Carmichael, G. R., Fernandes, S. D., Fu, Q., He, D., Klimont, Z., Nelson, S. M., Tsai, N. Y., Wang, M. Q., Woo, J. H., and Yarber, K. F.: An inventory of gaseous and primary aerosol emissions in Asia in the year 2000, J. Geophys. Res-Atmos., 108, 8809, doi:10.1029/2002JD003093, 2003.

Sun, Q. R. and Wang, M. R.: Ammonia Emission and Concentration in the Atmosphere over China, Scientia Atmospherica Sinica, 21, 79-87, 1997 (in Chinese).

Sutton, M. A., Nemitz, E., Erisman, J. W., Beier, C., Bahl, K. B., Cellier, P., de Vries, W., Cotrufo, F., Skiba, U., Di Marco, C., Jones, S., Laville, P., Soussana, J. F., Loubet, B., Twigg, M., Famulari, D., Whitehead, J., Gallagher, M. W., Neftel, A., Flechard, C. R., Herrmann, B., Calanca, P. L., Schjoerring, J. K., Daemmgen, U., Horvath, L., Tang, Y. S., Emmett, B. A., Tietema, A., Penuelas, J., Kesik, M., Brueggemann, N., Pilegaard, K., Vesala, T., Campbell, C. L., Olesen, J. E., Dragosits, U., Theobald, M. R., Levy, P., Mobbs, D. C., Milne, R., Viovy, N., Vuichard, N., Smith, J. U., Smith, P., Bergamaschi, P., Fowler, D., and Reis, S.: Challenges in quantifying biosphere-atmosphere exchange of nitrogen species, Environ. Pollut., 150, 125-139, doi:10.1016/j.envpol.2007.04.014, 2007.

Sutton, M. A., Oenema, O., Erisman, J. W., Leip, A., van Grinsven, H., and Winiwarter, W.: Too much of a good thing, Nature, 472, 159-161, 2011.

Vanbreemen, N., Driscoll, C. T., and Mulder, J.: Acidic Deposition and Internal Proton Sources in Acidification of Soils and Waters, Nature, 307, 599-604, 1984.

Van Damme, M., Clarisse, L., Heald, C. L., Hurtmans, D., Ngadi, Y., Clerbaux, C., Dolman, A. J., Erisman, J. W., and Coheur, P. F.: Global distributions, time series and error characterization of atmospheric ammonia $\left(\mathrm{NH}_{3}\right)$ from IASI satellite observations, Atmos. Chem. Phys., 14, 2905-2922, doi:10.5194/acp-14-29052014, 2014.

Van Damme, M., Erisman, J. W., Clarisse, L., Dammers, E., Whitburn, S., Clerbaux, C., Dolman, A. J., and Coheur, P. F.: Worldwide spatiotemporal atmospheric ammonia $\left(\mathrm{NH}_{3}\right)$ columns variability revealed by satellite, Geophys. Res. Lett., 42, 8660-8668, doi:10.1002/2015GL065496, 2015.

Vitousek, P. M., Naylor, R., Crews, T., David, M. B., Drinkwater, L. E., Holland, E., Johnes, P. J., Katzenberger, J., Martinelli, L. A., Matson, P. A., Nziguheba, G., Ojima, D., Palm, C. A., Robertson, G. P., Sanchez, P. A., Townsend, A. R., and Zhang, F. S.: Nutrient Imbalances in Agricultural Development, Science, 324, 15191520, 2009.

Wang, Q. B., Halbrendt, C., and Johnson, S. R.: Grain production and environmental management in China's fertilizer economy, J. Environ. Manage., 47, 283-296, 1996.

Wang, R., Tao, S., Wang, W. T., Liu, J. F., Shen, H. Z., Shen, G. F., Wang, B., Liu, X. P., Li, W., Huang, Y., Zhang, Y. Y., Lu, Y., Chen, H., Chen, Y. C., Wang, C., Zhu, D., Wang, X. L., Li, B. G., Liu, W. X., and Ma, J. M.: Black Carbon Emissions in China from 1949 to 2050, Environ. Sci. Technol., 46, 7595-7603, 2012.

Wang, S. W., Liao Qian, J. H., Hu, Y. T., and Yan, X. Y.: A Preliminary Inventory of $\mathrm{NH}_{3}-\mathrm{N}$ Emission and Its Temporal and Spatial Distribution of China, Journal of Agro-Environment Science, 28, 619-626, 2009 (in Chinese).

Wang, S. X., Xing, J., Jang, C. R., Zhu, Y., Fu, J. S., and Hao, J. M.: Impact Assessment of Ammonia Emissions on Inorganic Aerosols in East China Using Response Surface Modeling Technique, Environ. Sci. Technol., 45, 9293-9300, 2011.

Wang, W. X., Lu, X. F., Pang, Y. B., Tang, D. G., and Zhang, W. H.: Geographical distribution of $\mathrm{NH}_{3}$ emission intensities in China, Acta Scientiae Circumstantiae, 17, 3-8, 1997 (in Chinese).

Wang, Y., Zhang, Q. Q., He, K., Zhang, Q., and Chai, L.: Sulfatenitrate-ammonium aerosols over China: response to 2000-2015 emission changes of sulfur dioxide, nitrogen oxides, and ammonia, Atmos. Chem. Phys., 13, 2635-2652, doi:10.5194/acp-132635-2013, 2013.

Webb, J., Ryan, M., Anthony, S. G., Brewer, A., Laws, J., Aller, M. F., and Misselbrook, T. H.: Cost-effective means of reducing ammonia emissions from UK agriculture using the NARSES model, Atmos. Environ., 40, 7222-7233, 2006.

Xing, G. X. and Zhu, Z. L.: An assessment of N loss from agricultural fields to the environment in China, Nutr. Cycl. Agroecosys., 57, 67-73, 2000.

Xu, P., Zhang, Y. S., Gong, W. W., Hou, X. K., Kroeze, C., Gao, W., and Luan, S. J.: An inventory of the emission of ammonia from agricultural fertilizer application in China for 2010 and its high- 
resolution spatial distribution, Atmos. Environ., 115, 141-148, 2015.

Yamaji, K., Ohara, T., and Akimoto, H.: Regional-specific emission inventory for $\mathrm{NH}_{3}, \mathrm{~N}_{2} \mathrm{O}$, and $\mathrm{CH}_{4}$ via animal farming in south, southeast, and East Asia, Atmos. Environ., 38, 7111-7121, 2004.

Yan, X. Y., Akimoto, H., and Ohara, T.: Estimation of nitrous oxide, nitric oxide and ammonia emissions from croplands in East, Southeast and South Asia, Glob. Change Biol., 9, 1080-1096, 2003.

Yang, F., Tan, J., Zhao, Q., Du, Z., He, K., Ma, Y., Duan, F., Chen, G., and Zhao, Q.: Characteristics of $\mathrm{PM}_{2.5}$ speciation in representative megacities and across China, Atmos. Chem. Phys., 11, 5207-5219, doi:10.5194/acp-11-5207-2011, 2011.

Ye, X. N., Ma, Z., Zhang, J. C., Du, H. H., Chen, J. M., Chen, H., Yang, X., Gao, W., and Geng, F. H.: Important role of ammonia on haze formation in Shanghai, Environ. Res. Lett., 6, 024019, doi:10.1088/1748-9326/6/2/024019, 2011.

Zhang, F., Cheng, H. R., Wang, Z. W., Lv, X. P., Zhu, Z. M., Zhang, G., and Wang, X. M.: Fine particles $\left(\mathrm{PM}_{2.5}\right)$ at a CAWNET background site in Central China: Chemical compositions, seasonal variations and regional pollution events, Atmos. Environ., 86, 193-202, 2014.

Zhang, F. S., Chen, X. P., and Vitousek, P.: An experiment for the world, Nature, 497, 33-35, 2013.

Zhang, Q., Streets, D. G., Carmichael, G. R., He, K. B., Huo, H., Kannari, A., Klimont, Z., Park, I. S., Reddy, S., Fu, J. S., Chen, D., Duan, L., Lei, Y., Wang, L. T., and Yao, Z. L.: Asian emissions in 2006 for the NASA INTEX-B mission, Atmos. Chem. Phys., 9, 5131-5153, doi:10.5194/acp-9-5131-2009, 2009.
Zhang, W., Yu, Y. Q., Li, T. T., Sun, W. J., and Huang, Y.: Net Greenhouse Gas Balance in China's Croplands over the Last Three Decades and Its Mitigation Potential, Environ. Sci. Technol., 48, 2589-2597, 2014.

Zhang, Y. S., Luan, S. J., Chen, L. L., and Shao, M.: Estimating the volatilization of ammonia from synthetic nitrogenous fertilizers used in China, J. Environ. Manage., 92, 480-493, 2011.

Zhang, Y. X., Tao, S., Cao, J., and Coveney, R. M.: Emission of polycyclic aromatic hydrocarbons in China by county, Environ. Sci. Technol., 41, 683-687, 2007.

Zheng, J. Y., Yin, S. S., Kang, D. W., Che, W. W., and Zhong, L. J.: Development and uncertainty analysis of a high-resolution $\mathrm{NH}_{3}$ emissions inventory and its implications with precipitation over the Pearl River Delta region, China, Atmos. Chem. Phys., 12, 7041-7058, doi:10.5194/acp-12-7041-2012, 2012.

Zhou, F., Shang, Z. Y., Ciais, P., Tao, S., Piao, S. L., Raymond, P., He, C. F., Li, B. G., Wang, R., Wang, X. H., Peng, S. S., Zeng, Z. Z., Chen, H., Ying, N., Hou, X. K., and Xu, P.: A New HighResolution $\mathrm{N}_{2} \mathrm{O}$ Emission Inventory for China in 2008, Environ. Sci. Technol., 48, 8538-8547, 2014.

Zhu, L., Henze, D., Bash, J., Jeong, G.-R., Cady-Pereira, K., Shephard, M., Luo, M., Paulot, F., and Capps, S.: Global evaluation of ammonia bidirectional exchange and livestock diurnal variation schemes, Atmos. Chem. Phys., 15, 12823-12843, doi:10.5194/acp-15-12823-2015, 2015. 